\title{
Mechanical chest compressions in the coronary catheterization laboratory to facilitate coronary intervention and survival in patients requiring prolonged resuscitation efforts
}

Henrik Wagner ${ }^{1 *}$, Bjarne Madsen Hardig², Malin Rundgren ${ }^{3}$, David Zughaft ${ }^{1}$, Jan Harnek ${ }^{1}$, Matthias Götberg ${ }^{1}$ and Göran K. Olivecrona ${ }^{1}$

\begin{abstract}
Background: Resuscitation after cardiac arrest (CA) in the catheterization laboratory (cath-lab) using mechanical chest compressions (CC) during simultaneous percutaneous coronary intervention (PCI) is a strong recommendation in the 2015 European Resuscitation Council (ERC) guidelines. This study aimed at re-evaluating survival to hospital discharge and assess long term outcome in this patient population.

Methods: Patients presenting at the cath lab with spontaneous circulation, suffering CA and requiring prolonged mechanical CC during cath lab procedures between 2009 and 2013 were included. Circumstances leading to CA, resuscitation parameters and outcomes were evaluated within this cohort. For comparison, patients needing prolonged manual CC in the cath lab in the pre-mechanical CC era were evaluated. Six-month and one year survival with a mechanical CC treatment strategy from 2004 to 2013 was also evaluated.

Results: Thirty-two patients were included between 2009 and 2013 (24 ST-elevation myocardial infarction (STEMI), 4 non-STEMI, 2 planned PCl, 1 angiogram and 1 intra-aortic counter pulsation balloon pump insertion). Twenty were in cardiogenic shock prior to inclusion. Twenty-five were successfully treated with PCI. Median mechanical CC duration for the total cohort $(n=32)$ was 34 min (range 5-90), for the 15 patients with circulation discharged from the cath-lab, 15 min (range 5-90), and for the eight discharged alive from hospital, $10 \mathrm{~min}$ (range 5-52). Twenty-five percent survived with good neurological outcome at hospital discharge. Ten patients treated with manual CC were included with one survivor.
\end{abstract}

Discussion: Eighty-seven percent of the patients included in the mechanical CC cohort had their coronary or cardiac intervention performed during mechanical CC with an $80 \%$ success rate. This shows that the use of mechanical CC during an intervention does not seem to impair the interventional result substantially. The survival rate after one year was $87 \%$.

Conclusions: Among patients suffering CA treated with mechanical CC in the cath-lab, $25 \%$ had a good neurological outcome at hospital discharge compared to $10 \%$ treated with manual CC. Long term survival in patients discharged from hospital is good.

Keywords: Cardiac arrest, Resuscitation, Mechanical chest compressions, Percutaneous coronary intervention, Survival

\footnotetext{
* Correspondence: henrik.wagner@med.lu.se

'Department of Cardiology, Lund University, Lund, Sweden

Full list of author information is available at the end of the article
} 


\section{Background}

Since 2004, we have routinely used a mechanical chest compression (CC) device in cardiac arrest (CA) situations in the coronary catheterization laboratory (cathlab) when initial advanced resuscitation efforts have failed to obtain return of spontaneous circulation. A mechanical CC device can successfully be used to overcome the difficulties of performing manual $\mathrm{CC}$ during simultaneous percutaneous coronary intervention (PCI) [1]. There have been an increasing number of publications describing favourable outcomes with this treatment option, mostly small cohort studies and case reports [2-7]. We have previously documented a $25 \%$ survival rate in cerebral performance category 1 or 2 at hospital discharge using this treatment strategy [8]. Since 2015, the use of mechanical CC in CA situations in the cath-lab during simultaneous PCI is strongly recommended in the European Resuscitation Council (ERC) guidelines [9].

When implementing a new treatment strategy, it is important to evaluate the results over a long period of time. One of the difficulties with new treatment options is that they are often introduced without critical evaluation such as a randomized trial and without an organized implementation [10]. Over the years of using mechanical CC in the cath-lab in resuscitation efforts in combination with simultaneous PCI, we have noted several practical short-comings in the work-flow. This has led to the development of a more structured and more tightly conducted approach, which has been described in detail elsewhere [11]. We therefore continued to evaluate both short and long term outcomes in patients suffering CA treated with mechanical CC during an invasive cardiac/coronary procedure in a prospective manner between 9 April 2009 and 9 April 2013.

Other important factors are patients survival to hospital discharge and long term survival after CA in the cath-lab when they have been treated with prolonged advanced resuscitation efforts during an invasive cardiac/ coronary procedure. Ehlenbach et al. analysed the outcomes of CA, in individuals > 65 years of age suffering in-hospital CA, where the survival to discharge was $18.3 \%$ [12]. Girotra et al. studied in-hospital CA with an overall survival rate of $17 \%$ to discharge from hospital, with survival rates increasing from 13.7 to $22.3 \%$ at the end of the study [13]. However, CA cases occurring during a procedure in the operating room, in procedural suites or in the emergency department, were excluded [13]. A recently published study on in-hospital CA found a survival rate to discharge from hospital of $18.4 \%$ [14]. Further, in a Swedish study, the survival rate to discharge in in-hospital CA was found to be $37 \%$ and 1year survival among discharged patients was $84 \%$ [15]. Another study focusing on in-hospital CA, in an elderly cohort, > 65 years of age, concluded that among the patients discharged from hospital, $59 \%$ were alive 1 year after discharge [16]. In our previous patients series were mechanical CC during PCI was used [8] we did not explore the long term survival outcome. Therefore these patients were included in the long term follow up in the this publication.

The aim of this prospective study was to analyse circumstances leading to CA and resuscitation parameters, to re-evaluate survival to hospital discharge and to assess 6-month and 1 year survival in this patient population who suffer $\mathrm{CA}$ and require prolonged resuscitation with mechanical $\mathrm{CC}$ in combination with an invasive cardiac/ coronary procedure.

\section{Methods}

This prospective study was performed between 9 April 2009 and 9 April 2013 at the cath-lab at Skane University Hospital, Lund, Sweden. This is a tertiary centre in southern Sweden that performs PCIs $24 \mathrm{~h}$ a day, 7 days a week, and serves a population of 1.2 million. This study was approved by the local ethics review board (667/2009) and informed consent was obtained from survivors or from family members.

Among those who suffered a CA in the cath-lab, patients were included if resuscitation efforts has not solved the CA in a few minutes by defibrillation or drug treatment and there was consensus among the attending cardiologist, anaesthesiologist and the interventionist that mechanical CC was indicated. Cardiac arrest treatment prior to inclusion was performed according to the structural approach described previously, which also describes practical handling in the cath-lab setting including how to manoeuver the image amplifier, when and how to deploy the Mechanical CC device on the patient [11]. The reason for referral to the cath-lab for those who were included in the study was either a diagnostic coronary angiogram in a coronary stable state, non-STelevation myocardial infarction (non-STEMI), elective planned PCI, insertion of an intra-aortic balloon counter pulsation device and for primary PCI in patients suffering a STEMI.

For mechanical CC, the $\mathrm{LUCAS}^{\mathrm{T}} 2$ chest compression system (Physio-Control/Jolife AB, Lund, Sweden) was used. The patient cohort was evaluated in four outcome groups: patient characteristics for the whole group, for patients who expired in the cath-lab, for patients discharged from the cath-lab and for patients discharged from hospital. The predefined endpoints were return of spontaneous circulation when leaving the cath-lab, and hospital discharge in cerebral performance category 1 or 2 [17]. The cause of the referral to the cath-lab, culprit lesion, circulatory state at the time of arrival to the cathlab and rhythm at the time of the occurrence of the CA, were assessed in the 4 outcome groups. The number of 
PCIs during mechanical CC was assessed and successful PCI was defined according to the thrombolysis in myocardial infarction (TIMI) flow [18]. Treatment times with mechanical CC were calculated for all groups and compared across the four outcome groups. The use of vasoactive drugs was assessed.

As a comparison, outcome for 10 consecutive patients suffering CA who needed prolonged resuscitation with manual CC in the cath lab (from 1999 to 2003, the time period prior to the start of using mechanical CC in our lab) were analysed using the local hospital CA registry and medical files. Inclusion criteria were the same as for those treated with mechanical CC (i.e. patients suffering CA where initial early resuscitation efforts failed).

Long term follow up was done for patients discharged from hospital both from the previous retrospective registry study (1 January 2004 to 31 December 2008) [8] and those discharged from hospital in the current study.

\section{Statistical methods}

Continuous data are presented as mean \pm SD and median and range as appropriate. Categorical variables are presented as numbers or percentages. For non-parametric statistics, the Mann-Whitney $U$-test was used for calculating differences between the outcome groups, in age and mechanical CC time. A $p$-value $<0.05$ was considered significant.

\section{Results}

Thirty-two patients were included during this study period. For patient demographics see Table 1. Patient characteristics such as the indications for cath-lab procedure, culprit lesion, circulatory state upon arrival at the cath-lab, and rhythm when the CA occurred, are presented in Table 2.

In one specific patient, the reason for referral for the intra-aortic balloon counter pulsation insertion was therapy resistant ventricular tachycardia with cardiogenic shock. In the patients referred for planned PCI and nonSTEMI, complications such as, for example, thrombus formation, vessel rupture and dissection caused the CA. One of the patients with non-STEMI was in cardiogenic shock at the time of arrival at the cath-lab. The patient, who was referred for an elective pre-operative coronary angiogram for surgery on the aortic valve, deteriorated into pulseless electrical activity due to aortic stenosis and reduced systolic left ventricular function.

Seventeen patients expired in the cath-lab. Fifteen left the cath-lab with circulation, of whom eight were discharged from hospital with cerebral performance category 1-2. During the study period (9 April 2009 - 9 April 2013), 8738 patients were admitted to the cath-lab for an invasive cardiac/coronary procedure. In total, 3368 patients were evaluated with a coronary angiogram only and 5370 patents were treated with PCI (acute or elective) whereof 2728 were treated for STEMI. Of these, 116 patients were in cardiogenic shock when admitted to the cath-lab. There was no statistical age difference between the patients who expired in the cath-lab and those who were discharged from the cath-lab with circulation $(p=$ $0.37)$ and those discharged from hospital $(p=0.64)$. Successful PCI defined as TIMI-II-III or $<50 \%$ residual stenosis, PCI during mechanical CC and treatment time with mechanical CC are presented in Table 3. There was a statistically significant difference in time with mechanical CC when comparing patients who expired in the cath-lab to those discharged from the cath-lab with circulation $(p=$ $0.02)$ and to those discharged from hospital $(p=0.004)$. At least one vasoactive drug (norepinephrine, epinephrine or dobutamine) was administered either intermittently or as a continuous infusion) to 29 patients, and the majority received a combination of these drugs during the procedure.

\section{The manual CC treated group}

Ten patients (eight men) with a mean age of $68 \pm 6$ years suffered CA and required prolonged advanced resuscitation

Table 1 Patient demographics, concomitant diseases, smoking habits and previous coronary interventions

\begin{tabular}{lllll}
\hline & All patients & Expired Cath-lab & Discharged Cath-lab & Discharged Hospital \\
\hline Patient History & $n=32(\%)$ & $17(53)$ & $15(47)$ & $8(25)$ \\
Age & $71 \pm 13$ & $73 \pm 10$ & $68 \pm 15$ & $68 \pm 19$ \\
Gender (male) & $20(63)$ & 11 & 9 & 4 \\
Hypertension & $18(56 \%)$ & 9 & 9 & 7 \\
Diabetes & $8(25 \%)$ & 6 & 2 & 2 \\
Hyperlipidaemia & $9(28 \%)$ & 7 & 2 & 2 \\
Smoking/X-smoker & $14(44 \%)$ & 7 & 7 & 4 \\
Previous Ml & $9(28 \%)$ & 4 & 5 & 4 \\
Previous PCl & $3(9 \%)$ & 1 & 2 & 2 \\
Previous CABG & $4(13 \%)$ & 3 & 1 & 1 \\
\hline
\end{tabular}

Cath-lab coronary catheterization laboratory, $M I$ myocardial infarction, $P C l$ percutaneous coronary intervention, $C A B G$ coronary artery by-pass grafting 
Table 2 Indication for referral to the coronary catheterization laboratory, culprit lesion, circulatory state at arrival in the coronary catheterization laboratory, rhythm at the time of the cardiac arrest

\begin{tabular}{|c|c|c|c|c|}
\hline & All patients & Expired Cath-lab & Discharged Cath-lab & Discharged Hospital \\
\hline & $\mathrm{n}=32(\%)$ & $17(53)$ & $15(47)$ & $8(25)$ \\
\hline \multicolumn{5}{|c|}{ Indication for cath-lab procedure } \\
\hline STEMI & $24(75)$ & 15 & 9 & 4 \\
\hline non-STEMI & $4(13)$ & 1 & 3 & 2 \\
\hline Elective $\mathrm{PCl}$ & $2(6)$ & 1 & 1 & 1 \\
\hline Other & $1(3)$ & 0 & 1 & 1 \\
\hline Angiogram & $1(3)$ & 0 & 1 & 0 \\
\hline \multicolumn{5}{|c|}{ Culprit lesion in coronary patients } \\
\hline LM & $10(31)$ & 6 & 4 & 2 \\
\hline LAD & $12(38)$ & 7 & 5 & 2 \\
\hline LCX & $2(6)$ & 0 & 2 & 2 \\
\hline RCA & $6(19)$ & 4 & 2 & 1 \\
\hline Other & $2(6)$ & 0 & 2 & 1 \\
\hline \multicolumn{5}{|c|}{ Circulatory state at the arrival to the cath-lab } \\
\hline Cardiogenic shock & $20(62)$ & 12 & 8 & 2 \\
\hline \multicolumn{5}{|c|}{ Initial rhythm at cardiac arrest } \\
\hline VTNF & $5(16)$ & 1 & 4 & 2 \\
\hline PEA & $22(69)$ & 14 & 8 & 4 \\
\hline Asystole & $5(16)$ & 2 & 3 & 2 \\
\hline
\end{tabular}

Cath-lab coronary catheterization laboratory, STEMI ST-elevation myocardial infarction, non-STEMI non-ST-elevation myocardial infarction, $P C I$ percutaneous coronary intervention, $L M$ left main coronary artery, $L A D$ left anterior descendent coronary artery, $L C X$ left circumflex coronary artery, $R C A$ right coronary artery, $V T$ ventricular tachycardia, VF ventricular fibrillation, PEA pulseless electrical activity

efforts with manual $\mathrm{CC}$ in the cath-lab between 1 January 1999 and 31 December 2003. Eight of these were referred due to a STEMI; one patient had a nonSTEMI, and one patient had developed a ventricular septum defect due to a STEMI a few days earlier. Seven patients were in cardiogenic shock when admitted to the cath-lab. Two patients had a shockable rhythm at the time of the CA. Six patients were treated with PCI during manual CC, with $50 \%$ PCI success rate. The median time with manual $\mathrm{CC}$ for the whole group ( $n=10)$ was $20 \mathrm{~min}$ (range $15-75 \mathrm{~min}$ ), 20 min (range 15-75) for those who expired in the cath-lab $(n=6), 25$ min (range 15-60) for those discharged from the cath-lab $(n=4)$, and $15 \mathrm{~min}$ for the patient discharged from hospital in cerebral performance category $1(n=1)$. Comparison of data relating to patient history, indication for cath-lab procedure, culprit lesion, procedural data and the initial rhythm at

Table 3 Coronary catheterization laboratory procedural data

\begin{tabular}{lllll}
\hline & All patients & Expired Cath-lab & Discharged Cath-lab & Discharged Hospital \\
\hline Procedural data & $n=32(\%)$ & $17(53)$ & $15(47)$ & $8(25)$ \\
Angiography during MCC & $5(16)$ & 2 & 3 & 2 \\
PCl during MCC & $27(87)$ & 16 & 11 & 6 \\
PCl successful & $25(81)$ & 12 & 13 & 6 \\
PCl unsuccessful & $6(20)$ & 5 & 3 & 1 \\
Use of concomitant IABP & $12(38)$ & $42(10-75)$ & $15(5-90)$ & 4 \\
CC- time & $34(5-90)$ & 0 & 4 & $10(5-52)$ \\
Thoracic surgery & $4(13)$ & $P C$ P & 2
\end{tabular}

Cath-lab coronary catheterization laboratory, $P C I$ percutaneous coronary intervention, $M C C$ mechanical chest compression, IABP intra-aortic counter pulsation pump, $C C$ chest compression times are presented as median minutes (range) 
CA between the patients treated with mechanical CC and those treated with manual CC's can be seen in Table 4.

\section{Long term survival}

The long term survival for the present patient cohort that were discharged from hospital $(8(25 \%))$ was, 8 patients that (100\%) survived to 1 month after discharge, $8(100 \%)$ patients that survived to 6 month and 7 patients $(87 \%)$ were alive at 1 year, all in CPC 1-2. In our previous patients series the long term survival in those discharged from hospital (11 patients $(25 \%)$ ), was 10 patients $(91 \%)$ that survived to 1 month after discharge, 8 patients $(73 \%)$ that survived to 6 month and 8 patients (73\%) were alive at 1 year, all in CPC 1-2 (Fig. 1).

\section{Discussion}

In this prospective study evaluating the outcomes of patients treated with mechanical CC during a simultaneous cardiac/coronary procedure due to CA where normal advanced resuscitation efforts had failed, we found a $25 \%$ survival rate in cerebral performance category 1 or 2 at hospital discharge. These results verify similar survival results at hospital discharge as our previous retrospective study [8] and lend further support to the current ERC guideline [9]. The structured and more tightly conducted approach used in this second period did show an improvement in team work and resulted in a more calm and success oriented setting [11]. There is an increase in 1 year survival rate from $73 \%$ in the period between 1 January 2004 and 31 December 2008 to $87 \%$ in the current study that might reflect the new approach, but the figures should be handled with precaution since it is small numbers.

In-hospital CA could depend on a broad range of underlying conditions $[12-15,19,20]$. Reported survival rates to discharge from hospital after in-hospital CA vary widely, from 17 to $36 \%[12-15,19,20]$ and differences in inclusion and exclusion criteria are important when interpreting the results. In some studies, subgroups such as patients suffering a CA during a medical procedure or in the emergency department [13], or patients $<65$ years of age, have been excluded [12]. There are also important differences in background factors such as a high rate of initial shockable rhythm (49 and $39 \%)[15,20]$. As a comparison, the study presented here included patients without age restriction suffering $\mathrm{CA}$ in the cath-lab, who required prolonged advanced resuscitation efforts including mechanical CC during an intervention, and only $16 \%$ had an initial shockable rhythm. Thus, comparisons with the referred studies are delicate because of the important population differences.

In one registry report covering survival to hospital discharge after a CA in the cath-lab, survival was as high as
Table 4 Patient history, concomitant diseases, smoking habits and previous coronary interventions. Indication for referral to the coronary catheterization laboratory, culprit lesion, circulatory state at arrival to the coronary catheterization laboratory, rhythm at the time of the cardiac arrest. Coronary catheterization laboratory procedural data. Comparing those treated with Mechanical CPR and those treated with manual CPR

\begin{tabular}{|c|c|c|}
\hline & $\begin{array}{l}\text { Mechanical CC in the lab } \\
n=32\end{array}$ & $\begin{array}{l}\text { Manual CC in the lab } \\
n=10\end{array}$ \\
\hline \multicolumn{3}{|l|}{ Patient History } \\
\hline Age & $71( \pm 13)$ & $68( \pm 6)$ \\
\hline Gender (male) & 20 & 8 \\
\hline Hypertension & 18 & 1 \\
\hline Diabetes & 8 & 2 \\
\hline Hyperlipidemia & 9 & 1 \\
\hline Smoking/X-smoke & 14 & 2 \\
\hline Previous Ml & 9 & 2 \\
\hline Previous PCl & 3 & 1 \\
\hline Previous CABG & 4 & 1 \\
\hline \multicolumn{3}{|c|}{ Indication for cath lab procedure } \\
\hline STEMI & 23 & 8 \\
\hline non-STEMI & 4 & 1 \\
\hline Elective PCl & 2 & 0 \\
\hline Tamponade & 0 & 0 \\
\hline Other & 2 & 1 \\
\hline Angiogram & 1 & 0 \\
\hline \multicolumn{3}{|l|}{ Culprit lesion } \\
\hline LM & 10 & 1 \\
\hline LAD & 12 & 5 \\
\hline LCX & 2 & 1 \\
\hline RCA & 6 & 1 \\
\hline Other & 2 & 2 \\
\hline \multicolumn{3}{|l|}{ Procedural data } \\
\hline Angiography only & 5 & 1 \\
\hline PCI successful & 25 & 3 \\
\hline PCI Unsuccessful & 6 & 3 \\
\hline Use of IABP & 12 & 5 \\
\hline CC- time & $34(5-90)$ & $20(15-75)$ \\
\hline Cardiogenic shock & 20 & 7 \\
\hline \multicolumn{3}{|c|}{ Initial rhythm at cardiac arrest } \\
\hline VTNF & 5 & 2 \\
\hline PEA & 22 & 4 \\
\hline Asystole & 5 & 4 \\
\hline
\end{tabular}

Cath-lab coronary catheterization laboratory, STEMI ST-elevation myocardial infarction, non-STEMI non-ST-elevation myocardial infarction, $P C l$ percutaneous coronary intervention, $L M$ left main coronary artery, $L A D$ left anterior descendent coronary artery, $L C x$ left circumflex coronary artery, $R C A$ right coronary artery, $V T$ ventricular tachycardia, VF ventricular fibrillation, PEA pulseless electrical activity 


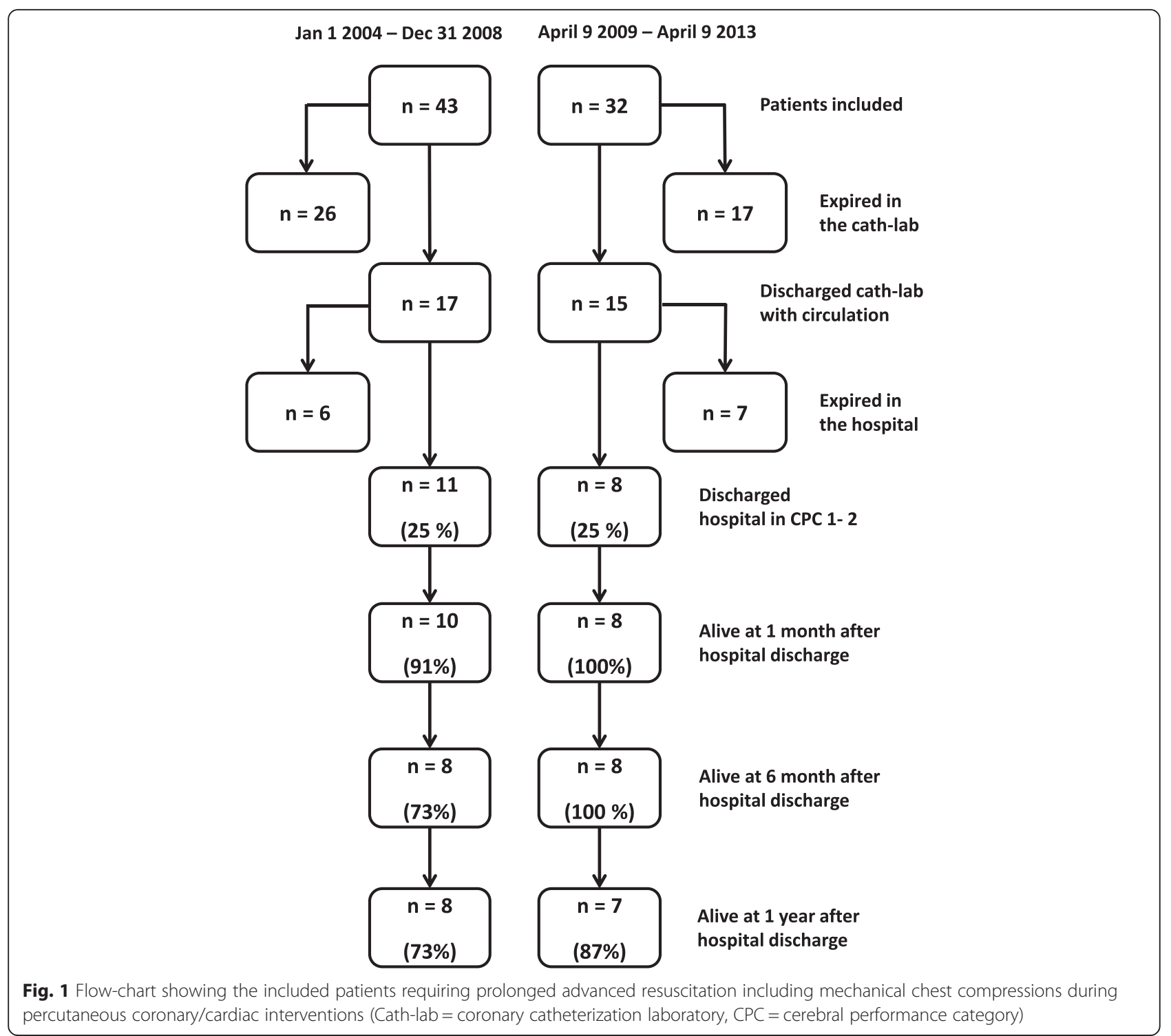

$65 \%$ [19]. The survival difference compared to our study may be caused by different inclusion criteria. In the report by Herlitz et al. [19], a large proportion of patients suffering a CA may have received one or two defibrillations and/or a few moments of manual CC. The incidence of reperfusion ventricular fibrillation in patients with STEMI treated by primary PCI in the cath-lab in our institution is $1.9 \%$ annually, with a survival rate of $81.7 \%$ at discharge from hospital when defibrillated early [21]. In the current study we have excluded these specific patients: hence making direct comparisons with the study by Herlitz et al. [19] and the study by Demidova et al. [21] in terms of survival are difficult.

In the current study, 27 patients (84\%) had a nonshockable rhythm at the time of the CA. This indicates that coronary ischemic-driven $\mathrm{CA}$ in this setting has a large proportion of patients presenting with a rhythm not treatable with defibrillation and that most of the patients with a ventricular fibrillation are easily treated with an early defibrillation as shown by Demidova et al. [21]. A similar percentage of ventricular fibrillation was seen in our previous study [8] and in our historical group treated with manual CC (Table 4). However, these percentages differ from other in-hospital studies, where 51 and $61 \%$ had an initial non-shockable rhythm [15, 20]. Again the cohorts studied in these papers differ, because all patients suffering a CA by any cause are included $[15,20]$ compared to the highly selected cohort in our current study. However, in the study by Nolan et al. there was a high amount of non-shockable rhythm (72.9\%) and only $16.9 \%$ had an initial shockable rhythm [14]. The cause is unclear, but one explanation 
might be that $56.6 \%$ of the CAs occurred in a general ward, likely without monitoring [14]. Thus the occurrence of the CA may not be instantly noticed, which may lead to the conversion of an initial ventricular fibrillation or a pulseless ventricular tachycardia to a non-shockable rhythm, but this remains speculative.

Twenty-five out of $31(80 \%)$ interventions were successful. Considering that $87 \%$ of the interventions were performed during mechanical CC, an $80 \%$ success rate is reasonable compared to the expected $90 \%$ success rate in primary PCI for STEMI [22]. In the previous study, there was a $76 \%$ PCI success rate [8]. Thus, the use of mechanical CC during simultaneous PCI does not appear to reduce PCI results substantially compared to primary PCI for STEMI.

In the 10 patients from the pre-mechanical $\mathrm{CC}$ era treated with manual CC, $10 \%$ survived to hospital discharge. One problem comparing historical data is that indications for referral to the cath-lab may have changed over time. This may be reflected by the fact that only 10 patients in four years needed prolonged resuscitation. The DANAMI-2 trial in 2003 showed superiority for primary PCI compared to fibrinolytic therapy in STEMIpatients [23], and Hochman et al. showed a survival benefit in patients in cardiogenic shock treated with early invasive strategy both in the short and long term perspective [24, 25]. The results of these studies may have increased referrals to the cath-lab of patients in a more severe cardio-vascular circulatory condition at greater risk of developing CA.

In the group treated with mechanical $\mathrm{CC}$, only two (25\%) of the patients discharged alive from hospital were in cardiogenic shock compared to 12 (60\%) who expired in the cath-lab. This mortality rate is higher compared to what was reported by Minha et al. where 29 \% with cardiogenic shock expired in the cath-lab [26]. In another large registry (patients suffering CA and resuscitated prior to PCI), CA was more common in patients with cardiogenic shock presenting with and without STEMI, where $82 \%$ of the deceased patients in the STEMI-group and $78 \%$ in the non-STEMI group were in cardiogenic shock [27]. One explanation for the high mortality rate in the group with cardiogenic shock might be that when a CA has occurred, the hemodynamic status prior to the CA reflects the severity of the disease, which may be important for achieving the return of spontaneous circulation.

The 1 year survival rate for patients in our previous study and current study discharged from the hospital in cerebral performance category $1-2$ was 73 and $87 \%$ respectively. This is higher in comparison to a large retrospective study of elderly patients where the survival rate after in-hospital CA was found to be $58 \%$ at one year [16] but similar to the study from Fredriksson et al. [15].
However, these studies included different causes of CA and survival was analysed at different time points, which makes comparison difficult.

When implementing new technologies in medical settings, it is important that this can be done methodologically and with thorough follow-up [10]. In the case of the implementation of mechanical CC in the cath-lab, there have been no randomized trials. Over the past ten years, we have included 75 patients and show a survival rate of $25 \%$ at discharge from hospital. With this number of patients and reproducible findings of successful interventions, we find the use of mechanical $\mathrm{CC}$ devices in the cath lab to be a reliable, safe and a valuable tool in the treatment of CA during PCI.

In an effort to further increase the survival rate for these patients, extracorporeal membranous oxygenation has been used in CA treatment situations with some success [28-30]. If implementing this strategy, the challenge will be to choose the "right" patients. In a Japanese study, the authors found that patients with refractory ventricular fibrillation and pulseless ventricular tachycardia without any evidence of developing signs of multiorgan dysfunction had a favourable outcome when treated with extracorporeal membranous oxygenation [31]. Most of those who died in our current study were in cardiogenic shock at the time of admission to the cath-lab. A reasonable thought is that the patients with cardiogenic shock should be selected for extracorporeal membranous oxygenation or Impella ${ }^{\circ}$, perhaps prior to the occurrence of the CA. Both the strategy with Impella ${ }^{\circ}$ as well with extracorporeal membranous oxygenation for prolonged resuscitation efforts are currently under evaluation in two randomized studies [32, 33].

\section{Limitations}

The study has some limitations. Firstly, it was not a randomized, controlled study. However, performing a randomized study in this setting and comparing mechanical $\mathrm{CC}$ to manual $\mathrm{CC}$ during simultaneous $\mathrm{PCI}$ might be controversial, since it is exceedingly difficult to perform manual CC during simultaneous $\mathrm{PCI}$ and the $\mathrm{CC}$ provider would be exposed to unacceptably high amounts of X-ray radiation. The numbers of patients treated with manual CC during prolonged CA in the cath-lab are small, which make comparison difficult, but the time period covering the pre-mechanical CC era could not be extended since the in hospital CA registry started in 1999. Having a new treatment strategy for this group of patients in the need of prolonged resuscitation might influence the decision to treat more patients which also can affect results. The control patients were also treated during a time period were poorer post resuscitation care was available, which could have an effect on the long term outcome in this group. Despite the limitation of 
being a small study (only $0.09 \%$ of the patients who were referred for primary PCI suffered CA and required prolonged resuscitation including mechanical $\mathrm{CC}$ ), this is the second-largest prospective single centre case series $(n=32)$ describing the use of mechanical CC devices in the cath-lab.

\section{Conclusion}

This study confirms the results of our earlier study, which showed a survival rate at hospital discharge of $25 \%$ in patients treated with mechanical CC during PCI and who arrived at the cath-lab with spontaneous circulation. Furthermore, there was good long term survival rate with good neurological outcome among patients discharged from the hospital.

\section{Competing interests}

Henrik Wagner has received lecture honoraria from Physio-Control/Jolife AB, Lund, Sweden.

Bjarne Madsen Hardig is an employee of Physio-Control/Jolife AB, Lund, Sweden.

Göran K. Olivecrona has received lecture honoraria from Physio-Control/Jolife $A B$, Lund, Sweden

No other authors have any conflict of interest.

\section{Authors' contributions}

HW has drafted the concept and design of the study, acquisition and evaluation of data, drafted the manuscript and was the main writer and has participated in the treatment of the patients. BMH participated in the concept and design of the study, statistical analysis, of data as well as critical evaluation of the manuscript. MR has participated in the treatment of the patients and critically evaluated the manuscript. MG has participated in the treatment of the patients and critically evaluated the manuscript. DZ has participated in the treatment of the patients and critically evaluated the manuscript. JH has participated in the treatment of the patients and critically evaluated the manuscript. GOA has drafted the concept and design of the study and has participated in the treatment of the patients and critically evaluated the manuscript. All authors read and approved the final manuscript.

\section{Acknowledgement}

The authors thank Registered Nurse Hans Olson, Department of Anaesthesiology and Intensive Care, Lund University, Lund, Sweden, for help in collecting data. This study has been funded by the Swedish Heart and Lung Foundation, Skåne County Council's Research and Development Foundation and the Laerdal Foundation.

\section{Author details}

${ }^{1}$ Department of Cardiology, Lund University, Lund, Sweden. ${ }^{2}$ Physio-Control Sweden/Jolife AB, Lund, Sweden. ${ }^{3}$ Department of Anaesthesiology and Intensive Care, Lund University, Lund, Sweden.

Received: 29 July 2015 Accepted: 8 January 2016

Published online: 21 January 2016

\section{References}

1. Azman KJ, Gorjup V, Noc M. Rescue percutaneous coronary intervention during cardiopulmonary resuscitation. Resuscitation. 2004;61 (2):231-6.

2. Nielsen N, Sandhall L, Schersten F, Friberg H, Olsson SE. Successful resuscitation with mechanical $\mathrm{CPR}$, therapeutic hypothermia and coronary intervention during manual CPR after out-of-hospital cardiac arrest. Resuscitation. 2005;65(1):111-3.

3. Grogaard HK, Wik L, Eriksen M, Brekke M, Sunde K. Continuous mechanical chest compressions during cardiac arrest to facilitate restoration of coronary circulation with percutaneous coronary intervention. J Am Coll Cardiol. 2007;50(11):1093-4.

4. Larsen Al, Hjornevik AS, Ellingsen CL, Nilsen DW. Cardiac arrest with continuous mechanical chest compression during percutaneous coronary intervention. A report on the use of the LUCAS device. Resuscitation. 2007; 75(3):454-9.

5. Agostoni P, Cornelis K, Vermeersch P. Successful percutaneous treatment of an intraprocedural left main stent thrombosis with the support of an automatic mechanical chest compression device. Int J Cardiol. 2008;124(2):e19-21.

6. Bonnemeier H, Simonis G, Olivecrona G, Weidtmann B, Gotberg M, Weitz G, et al. Continuous mechanical chest compression during in-hospital cardiopulmonary resuscitation of patients with pulseless electrical activity. Resuscitation. 2011;82(2):155-9.

7. Azadi N, Niemann JT, Thomas JL. Coronary imaging and intervention during cardiovascular collapse: use of the LUCAS mechanical CPR device in the cardiac catheterization laboratory. J Invasive Cardiol. 2012;24(2):79-83.

8. Wagner H, Terkelsen CJ, Friberg H, Harnek J, Kern K, Lassen JF, et al. Cardiac arrest in the catheterisation laboratory: a 5-year experience of using mechanical chest compressions to facilitate $\mathrm{PCl}$ during prolonged resuscitation efforts. Resuscitation. 2010;81(4):383-7.

9. Truhlár A, Deakin CD, Soar J, Khalifa GEA, Alfonzo A, Bierens JJLM, et al, European Resuscitation Council Guidelines for Resuscitation 2015Section 4. Cardiac arrest in special circumstances. Resuscitation. 2015;95:148-201.

10. Grol R, Grimshaw J. From best evidence to best practice: effective implementation of change in patients' care. Lancet. 2003;362(9391):1225-30.

11. Wagner H, Rundgren M, Madsen Hardig B, Kern K, Zughaft D, Harnek J, et al. A structured approach for treatment of prolonged cardiac arrest cases in the coronary cathetrization laboratory using mechanical chest compressions. Int J Cardiovasc Res. 2013;2(4):1-7.

12. Ehlenbach WJ, Barnato AE, Curtis JR, Kreuter W, Koepsell TD, Deyo RA, et al. Epidemiologic study of in-hospital cardiopulmonary resuscitation in the elderly. N Engl J Med. 2009;361(1):22-31.

13. Girotra S, Nallamothu BK, Spertus JA, Li Y, Krumholz HM, Chan PS. Trends in survival after in-hospital cardiac arrest. N Engl J Med. 2012;367(20):1912-20.

14. Nolan JP, Soar J, Smith GB, Gwinnutt C, Parrott F, Power S, et al. Incidence and outcome of in-hospital cardiac arrest in the United Kingdom National Cardiac Arrest Audit. Resuscitation. 2014;85(8):987-92.

15. Fredriksson M, Aune $\mathrm{S}$, Thoren AB, Herlitz J. In-hospital cardiac arrest-an Utstein style report of seven years' experience from the Sahlgrenska University Hospital. Resuscitation. 2006:68(3):351-8.

16. Chan PS, Spertus JA, Nallamothu BK. Long-term outcomes in elderly survivors of cardiac arrest. N Engl J Med. 2013;368(25):2438-9.

17. Jennett B, Bond M. Assessment of outcome after severe brain damage. Lancet. 1975;1(7905):480-4.

18. Nicklas JM, Diltz EA, O'Neill WW, Bourdillon PD, Walton Jr JA, Pitt B. Quantitative measurement of coronary flow during medical revascularization (thrombolysis or angioplasty) in patients with acute infarction. J Am Coll Cardiol. 1987:10(2):284-9.

19. Herlitz J. Swedish Cardiopulmonary Resuscitation Registry. 2013. Yearly report of cardiac arrest reported to the Swedish cardiopulmonary resucitation registry.

20. Wallmuller C, Meron G, Kurkciyan I, Schober A, Stratil P, Sterz F. Causes of in-hospital cardiac arrest and influence on outcome. Resuscitation. 2012; 83(10):1206-11.

21. Demidova MM, Carlson J, Erlinge D, Platonov PG. Predictors of ventricular fibrillation at reperfusion in patients with acute ST-elevation myocardial infarction treated by primary percutaneous coronary intervention. Am J Cardiol. 2014;115(4):417-22.

22. Tadel-Kocjancic S, Zorman S, Jazbec A, Gorjup V, Zorman D, Noc M. Effectiveness of primary percutaneous coronary intervention for acute STelevation myocardial infarction from a 5 -year single-center experience. Am $J$ Cardiol. 2008:101(2):162-8.

23. Andersen HR, Nielsen TT, Rasmussen $K$, Thuesen L, Kelbaek $H$, Thayssen P, et al. A comparison of coronary angioplasty with fibrinolytic therapy in acute myocardial infarction. N Engl J Med. 2003;349(8):733-42.

24. Hochman JS, Sleeper LA, Webb JG, Sanborn TA, White HD, Talley JD, et al. Early revascularization in acute myocardial infarction complicated by cardiogenic shock. SHOCK Investigators. Should We Emergently Revascularize Occluded Coronaries for Cardiogenic Shock? N Engl J Med. 1999;341(9):625-34.

25. Hochman JS, Sleeper LA, White HD, Dzavik V, Wong SC, Menon V, et al. One-year survival following early revascularization for cardiogenic shock. JAMA. 2001;285(2):190-2.

26. Minha S, Barbash IM, Dvir D, Ben-Dor I, Loh JP, Pendyala LK, et al. Correlates for mortality in patients presented with acute myocardial infarct complicated by cardiogenic shock. Cardiovasc Revasc Med. 2014;15(1):13-7. 
27. Gupta N, Kontos MC, Gupta A, Dai D, Vetrovec GW, Roe MT, et al. Characteristics and outcomes in patients undergoing percutaneous coronary intervention following cardiac arrest (from the NCDR). Am J Cardiol. 2014;113(7):1087-92.

28. Arlt M, Philipp A, Voelkel S, Schopka S, Husser O, Hengstenberg C, et al. Early experiences with miniaturized extracorporeal life-support in the catheterization laboratory. Eur J Cardiothorac Surg. 2012;42(5):858-63.

29. Kagawa E, Dote K, Kato M, Sasaki S, Nakano Y, Kajikawa M, et al. Should we emergently revascularize occluded coronaries for cardiac arrest? Rapidresponse extracorporeal membrane oxygenation and intra-arrest percutaneous coronary intervention. Circulation. 2012;126(13):1605-13.

30. Mooney MR, Hildebrandt D, Feldman D, Sun B, Rilla D, Wang Y, et al. Level 1 shock team-early experince in ECMO use as a rescue device in cardiac arrest from STEMI in the cardiac catheterization laboratory. J Am Coll Cardiol. 2013. doi:10.1016/S0735-1097(13)60018-2.

31. Aoyama N, Imai H, Kurosawa T, Fukuda N, Moriguchi M, Nishinari M, et al. Therapeutic strategy using extracorporeal life support, including appropriate indication, management, limitation and timing of switch to ventricular assist device in patients with acute myocardial infarction. J Artif Organs. 2013;17(1):33-41.

32. Danshockinvestigatorerne T. of cardiogenic shock with percutanous mechanical circulatory support. Ugeskr Laeger. 2013;175(4):205-8.

33. Belohlavek J, Kucera K, Jarkovsky J, Franek O, Pokorna M, Danda J, et al. Hyperinvasive approach to out-of hospital cardiac arrest using mechanical chest compression device, prehospital intraarrest cooling, extracorporeal life support and early invasive assessment compared to standard of care. A randomized parallel groups comparative study proposal. "Prague OHCA study". J Transl Med. 2012;10:163.

\section{Submit your next manuscript to BioMed Central} and we will help you at every step:

- We accept pre-submission inquiries

- Our selector tool helps you to find the most relevant journal

- We provide round the clock customer support

- Convenient online submission

- Thorough peer review

- Inclusion in PubMed and all major indexing services

- Maximum visibility for your research

Submit your manuscript at www.biomedcentral.com/submit 